\title{
Factors influencing individual and community participation in the control of tsetse flies and human African trypanosomiasis in Urambo District, Tanzania
}

\author{
C. SINDATO ${ }^{1 *}$, E.N. KIMBITA ${ }^{2}$ and S.N. KIBONA ${ }^{1}$ \\ ${ }^{1}$ National Institute for Medical Research, P.O. Box 482, Tabora, Tanzania \\ ${ }^{2}$ Sokoine University of Agriculture, Department of Veterinary Microbiology and Parasitology, P.O. Box 3019, Morogoro, \\ Tanzania
}

\begin{abstract}
This study was carried out to assess the knowledge and level of individual and community participation in the control of Human African trypanosomiasis in Urambo District, western Tanzania. Semi structured questionnaires were used to collect information from individuals at house hold level. Retrospective data of HAT was sought from the medical officers in-charge of health facilities. The results indicate that, $191(90.5 \%, \mathrm{n}=211)$ individuals knew tsetse flies and 187 $(88.6 \%, \mathrm{n}=211)$ knew HAT. All nine key informants reported that, the communities were aware of HAT while seven key informants reported that, the communities were aware of health risks associated with tsetse bites in human. There was poor knowledge about the role played by animals in the transmission of HAT $(26.7 \%, \mathrm{n}=187)$. Majority of those who knew HAT $(\mathrm{n}=187)$ were willing to contribute labour $(70.1 \%)$ and money $(64.2 \%)$ to tsetse and HAT control whereas amongst those who knew tsetse flies, $66.5 \%$ and $60.7 \%$ were willing to contribute labour and money, respectively. Amongst those who knew any HAT control technique $(\mathrm{n}=108), 78.7 \%$ and $82.4 \%$ were willing to contribute money and labour respectively. A total of 454 cases of HAT were reported in the area from 1999 to 2006 . It is concluded that, the factors influencing individual and community participation include the knowledge of tsetse, HAT and control measures.
\end{abstract}

Key words: Trypanosomiasis, tsetse fly, knowledge, community participation, Tanzania

\section{Introduction}

Human African trypanosomiasis (HAT) is a zoonosis and remains an important public health problem in Tanzania. The disease is endemic in Urambo, Mpanda, Babati, Monduli, Hanang, Nkasi, Kasulu, Kibondo and Chunya districts (Kibona et al, 2002; Malele et al., 2006; Kinug'hi et al., 2006). In Tanzania the control of tsetse and HAT includes use of targets, traps, pour on, treatment of the infected animals and human beings. Besides the non-living stationary targets, insecticidetreated cattle (moving targets) have been used for tsetse control in Kagera Region (Hargrove et al., 1999). An equally important aspect in the control of tsetse flies and HAT is the active community involvement. However, community participation in disease control is minimal in many areas of Tanzania and this has been partly attributed to community knowledge gaps about the disease and the vectors (Mboera et al., 2007).

Community participation has been defined as 'a process in which people take part in decision making in the institutions, programmes and environments that affect them (Heller, 1984). Community participation is usually conceptualised as a process by which members of the communities individually or collectively assume increased responsibility for assessment of their own needs, and once these are agreed upon, identify potential situations to problems, and plan strategies by which these solutions may be realised (Bermejo \& Bekui, 1993). Community participation in health programmes has been found to be the critical towards their success (Mlozi et al., 2006). The benefits of community participation for health programmes, including increased coverage, efficiency, effectiveness, equity, sustainability and self-reliance, are widely accepted (WHO, 1991). In its 55 ${ }^{\text {th }}$ WHO Regional Committee for Africa held in August 2005, approved among others, strategies to advocate for an increased awareness of the risks and consequences of HAT, with emphasis on community participation at all stages of the fight against this disease (http://www.afro.who.int/dde/publications/trypanosomiasis resolution.pdf).

Traditionally, most tsetse control programmes in Africa have been managed and carried out by central governments through tsetse control units. However, most such programmes have been expensive and not sustainable. The new techniques, offer possibilities for new management approaches. Tsetse control programmes using traps and targets which have been initiated to date have involved local populations in various ways. These include the creation of local awareness about the problems of tsetse and trypanosomiasis and the function of the technology in order to reduce theft and vandalism; the provision of traps and targets or component materials by governments or other agencies, with local communities undertaking partial or total responsibility for trap and target construction, deployment and maintenance; the employment of local people to deploy or maintain the technology; the hiring of private contractors to maintain target barriers;

* Correspondence: Dr. Calvin Sindato; Email: kndato@yahoo.co.uk 
the provision of technical assistance following local requests, with community responsibility for financing control measures and undertaking all deployment and maintenance activities with minimal outside facilitation and support (Ssennyonga, 1994; Swallow \& Woudyalew, 1994; Dietvorst, 1995; Omolo et al., 1995; Mwangi, 1996; Barrett, 1997; Echessah et al., 1997).

This study therefore aimed at investigating the factors influencing individuals and community participation in the control of tsetse and HAT in Urambo district, assuming that individual and community participation would promote sustained control efforts while reducing control expenditure. The data obtained through this study is expected to help policy makers and planners in designing and implementing effective and sustainable community based tsetse and HAT control programmes.

\section{Materials and Methods}

\section{Study area}

The study was carried out in Kaliua Division in Urambo District ( $4^{0} 00^{\prime}-5^{0} 53^{\prime} \mathrm{S}$; $\left.30^{0} 00^{\prime}-32^{0} 37^{\prime} \mathrm{E}\right)$ in western Tanzania. Urambo District has a population estimated at 370,796. The main economic activities of the residents include subsistence agriculture, honey gathering and livestock keeping. Urambo was purposely selected for this study because of the recent re-emergence of HAT in the district (Kibona et al., 2002). Nine villages were involved in the study. These included Kangembe, Kombe, Mtakuja, Tuombe-Mungu, Ukumbisiganga, Ulindwanoni, Usinga, Usinge and Zugimlole.

\section{Study population and data collection}

Nine villages were conveniently selected from the 11 villages where the disease has re-emerged in recent years. Semi-structured questionnaires comprising of both open and closed questions were used (faceto-face) to collect information from the willing individuals in the randomly selected households. The questionnaire was administered in Kiswahili, however, whenever the interviewee was found to be not fluent in Kiswahili, the questions were translated into his/her local language.

Retrospective data on the situation of HAT was sought from the medical records at Kaliua Health Centre and Urambo District Hospital. These retrospective data are based on summary data that cannot be linked to individual patient and/or individual households/ members of the community.

\section{Data analysis}

Data collected were coded, entered into MS Excel spread sheet and analysed using the Statistical Package for Social Sciences version 12 (SPSS, 2003). Descriptive statistics were carried out to measure relative frequencies of the variables. Analytic statistics was applied to assess the association/relationship between the variables. Correlation was employed to measure the degree of association/relationship between variables. Statistical significance of parameter estimate was considered at $P \leq 0.05$.

\section{Results}

\section{Characteristics of the individual respondents}

A total of 211 (males $=54 \%$, females $=46 \%$ ) individuals were interviewed. The overall average mean age of respondents was 39.42 years (range $=18-95$ years, SEM = 1.04). Crop production was the main source of income for the majority of the respondents $(96.2 \%)$. A total of $143(67.8 \%)$ respondents had primary school education and $175(82.9 \%)$ had average monthly income below US\$ 50. Majority (69.6\%) of respondents were keeping a least a chicken, followed by goats $(15.2 \%)$, cattle $(1.9 \%)$, sheep $(0.5 \%)$ and other domestic animals (4.7\%).

\section{Knowledge, perception and practices towards tsetse flies and $\mathrm{HAT}$}

Of the 211 respondents, $191(90.5 \%)$ knew tsetse flies; majority of them $(81.2 \%, n=191)$ described tsetse fly as an insect resembling housefly. Other descriptions about tsetse fly were reported as biting fly (13.1\%), bee-like fly $(2.6 \%)$, mosquito-like fly $(1.6 \%)$ and tick-like fly $(0.5 \%)$. Two $(1 \%)$ respondents could not describe the fly. Majority (81.2\%) of those who knew tsetse fly could associate it with bushes/forest while few $(18.8 \%)$ with both bushes/forest and peridomestic environment. The association of tsetse fly and peridomestic environment was mainly reported among respondents $(81.8 \%, \mathrm{n}=22)$ in Usinga village close to Ugala Game reserve.

Among respondents who knew tsetse fly, 71.2\% reported to have experienced at least a tsetse bite in their lifetime. Most of them (90.0\%) knew the health risks associated with tsetse bite in human while $38.7 \%$ knew the health risks associated with tsetse bite in animals. The frequently mentioned health risks associated with tsetse bite in humans were sleeping sickness $(60.1 \%)$, fever $(22.5 \%)$, malaria $(2.9 \%)$ and headache (1.7\%). Of the respondents, $88.6 \%$ knew human African trypanosomiasis (HAT), of which $84.5 \%$ 
$(\mathrm{n}=187)$ knew that it is transmitted by tsetse fly. HAT transmission was mentioned to be through blood transfusion or mosquito bite by $1.1 \%$ of the respondents. There was poor knowledge about the role played by animals in the transmission of HAT $(26.7 \%, \mathrm{n}=187)$. The knowledge of HAT was similar among male and female respondents $(P>0.05)$. Similarly, there was no significant correlation between the level of education and knowledge of tsetse flies, HAT and its transmission $(P>0.05)$.

Of all the respondents who knew HAT $(n=187)$, $1.1 \%$ and $2.1 \%$ reported to have at least one family member suffered from the disease in 2005 and 2006, respectively. Of the affected individuals, 5 recovered following treatment while one died under treatment. The signs and symptoms of HAT included fever (68.5\%), headache (37.8\%), mental disorders (36.4\%), general body weakness (25.9\%), abnormal sleep (22.4\%), back-ache (9.8\%), sight impairment (5.6\%), loss of appetite (3.5\%), stomach-ache (2.8\%) and dizziness $(1.4 \%)$. All nine key informants reported that, the communities were aware of HAT, but only seven of them reported that, the communities were aware of health risks associated with tsetse bites.

Overall, $98.1 \%$ of individual respondents and seven key informants in all villages reported that, the community frequently visits health care facilities whenever any member of the family suffers from health problems including HAT. However, individuals from Usinga had to travel for up to $30 \mathrm{~km}$ to reach the nearest health facility. None of the nearest health facilities mentioned were found to be capable of diagnosing and managing HAT cases because of lacking either or both the health care professionals and the diagnostic facilities. HAT patients were referred to Kaliua Health Centre located at $90 \mathrm{~km}$ from Usinga and Usinge villages. Respondents from
Usinga village $(\mathrm{n}=22)$ frequently mentioned lack of reliable transport $(72.7 \%)$, long distance to the health facility $(22.7 \%)$ and costs associated with consultations and accommodation of patients $(22.7 \%)$ as the major hindrances in seeking care at Kaliua. Lack of accommodation was also mentioned by respondents from other villages (Ukumbisiganga $=16.7 \%, \mathrm{n}=18$; Ulindwanoni $=15.8 \%, \mathrm{n}=19 ;$ Zugimlole $=4.5 \%, \mathrm{n}=$ 22; Tuombemungu $=3.6 \%, \mathrm{n}=28$ ).

Majority $(80.6 \%)$ of the respondents were aware of the gender that is most likely to suffer from HAT. One respondent mentioned either one or both genders whereby adults males $(97.1 \%, \mathrm{n}=170)$ were the most likely to suffer from HAT followed by adult females $(48.2 \%)$, young males $(27.1 \%)$ and young females (26.5\%). The similar trend was reported by the key informants whereby all nine, three and two key informants mentioned adult males, adult females and young males and females respectively to be the most likely to suffer from HAT. The visit to tsetse infested areas was the main likelihood reason (68.8\%) of contracting HAT. The likelihood of contracting HAT for those living in areas infested with tsetse flies was only associated with $8.8 \%$ of the respondents. However, $63.6 \%$ $(\mathrm{n}=22)$ of the respondents in Usinga (close to Ugala Game Reserve) associated HAT with living in areas infested with tsetse flies. Eight key informants mentioned the main reason for the suffering likeliness to be visiting tsetse infested areas. Activities frequently mentioned by individual respondents who were aware of HAT $(\mathrm{n}=187)$ to expose an individual to tsetse bite were timbering and honey gathering (Table 1). The activities mentioned by key informants to expose an individual to tsetse bite were timbering (6), honey gathering (6), fishing (3), agriculture (2), hunting (2), herding (2) and fire wood gathering (1).

Table 1: Number (\%) of respondents on the activities that expose a person to tsetse fly bites

\begin{tabular}{ll}
\hline Activity & Individual respondent $(\mathbf{n}=\mathbf{1 8 7})$ \\
\hline Timbering & $57.8 \%$ \\
Honey gathering & $54.5 \%$ \\
Fishing & $31.6 \%$ \\
Agriculture & $27.8 \%$ \\
Firewood gathering & $17.6 \%$ \\
Hunting & $13.9 \%$ \\
Herding & $4.8 \%$ \\
Charcoal making & $8.0 \%$ \\
\hline
\end{tabular}


Amongst few $(26.7 \%, \mathrm{n}=187)$ individual respondents who were aware of the role played by domestic and wild animals in the epidemiology of HAT mentioned wild animals including elephant $(5.3 \%)$, baboon $(4.3 \%)$, antelope and kudu (3.7\%), buffalo (2.1\%), giraffe, zebra and lion (1.6\%). The mentioned domestic animals were cattle $(8.6 \%)$, dogs $(4.3 \%)$, goats $(3.2 \%)$ and sheep (1.6\%). Seven key informants reported that, the community was not aware of the role played by domestic and wild animals in the epidemiology of HAT.

According to the respondents, the major impacts of trypanosomiasis in human and animals included death of the affected person (74.3\%), expenses in treating sick person (49.9\%), reduction in agricultural production due to loss of man power resource $(26.2 \%)$, death of the affected animal $(9.6 \%)$, expenses in treating sick animals $(0.5 \%)$ and transmitting the disease from one person to another $(0.5 \%)$. The frequently mentioned sources of information amongst those individuals who knew HAT were HAT patients (60.4\%), health care personnel $(24.6 \%)$, relatives $(19.3 \%)$ and villagers meetings $(3.2 \%)$. The frequently mentioned kind of information received from the above mentioned sources were information about clinical signs and symptoms $(78.6 \%)$, the right place for treatment (44.9\%) and control/prevention (29.9\%). The sources of information to the community that were frequently mentioned by key informants were the patients (7), health care personnel (3) and village meetings (2).

The most reported disease of major public health problem was malaria $(62.6 \%, \mathrm{n}=211)$. Overall, $43.6 \%$ of respondents from all 9 villages reported HAT to be amongst the diseases of major public health problems. The villages in which HAT was frequently reported to be amongst the major public health problems were Usinga $(100 \%, \mathrm{n}=22)$, Kangeme $(95 \%, \mathrm{n}=20)$, Ukumbisiganga $(94.4 \%, \mathrm{n}=18)$ and Kombe $(72.0 \%$, $\mathrm{n}=25)$. Nine key informants mentioned HAT and malaria to be amongst the diseases of major public health importance in the area. Other public health problems mentioned by key informants were diarrhoeal diseases HIV/AIDS and eye diseases.

\section{Factors influencing individual and community participation}

Of 108 individuals who were aware of any control measure of HAT, $79.6 \%$ mentioned the use of insecticide impregnated targets/traps (IIT) of which $86.0 \%$, $57.0 \%, 81.4 \%$ and $96.5 \%(\mathrm{n}=86)$ respectively, report- ed this control measure to be effective, fairly available, easy to use and acceptable to the community. Other control measures were screening (20.4\%), insecticide spray $(1.9 \%)$ and bush clearing $(0.9 \%)$.

Of those individuals who knew any HAT control measure $(n=108)$ only $16(14.8 \%)$ respondents reported to have participated in at least one control measure of which $93.8 \%$ and $6.2 \%$ participated in the use of IIT and medical screening respectively. Of those who participated in the use of IIT, $53.3 \%$ and $46.7 \%$ were involved only once and more than once respectively while a respondent who participated in the medical screening was involved only once. Of those who reported to have not participated $(n=92)$ in any control measure, $57.6 \%$ mentioned at least one reason, of which majority $(86.8 \%, \mathrm{n}=53)$ reported that, they were not given an opportunity to participate.

The most preferred HAT control methods by the key informants were the use of IIT (88.9\%) and aerial insecticide spray $(11.1 \%)$ whereby the respective mentioned reasons for the preference were the previous effectiveness of IIT in reducing the tsetse fly population. All the key informants mentioned the method to be effective, easy to apply and acceptable to the community.

Thirteen percent and $9.3 \%$ of those who were aware of any HAT control measure reported to have at least once contributed resources to the control activities in terms of labour and money, respectively and all were from Ukumbisiganga, Zugimlole, Usinga and Kangeme villages. Majority of those who knew $\operatorname{HAT}(\mathrm{n}=187)$ were more willing to contribute labour $(70.1 \%)$ and money $(64.2 \%)$ than those who did not know the disease $(P<0.01)$. Amongst those who knew tsetse flies, $66.5 \%$ and $60.7 \%(\mathrm{n}=191)$ were willing to contribute labour and money, respectively than those who did not know tsetse flies $(P<0.01)$ (Figure 1). Amongst those who knew any HAT control technique, $78.7 \%$ and $82.4 \%(n=108)$ were more willing to contribute money and labour, respectively than those who were not aware of any control method $(P<0.01)$. Those who knew tsetse can transmit HAT $(\mathrm{n}=158)$ were more willing to contribute labour (73.4\%) than those who did not know $(P<0.01)$. There was no significant difference between those who knew and those who did not know that tsetse can transmit HAT and their willingness to contribute money $(P>0.05)$. There was no significant correlation between the average monthly income of the respondents and the willingness to contribute to labour and money $(P>0.05)$. Overall, 
males were more willing to contribute labour $(P<0.01)$ and money $(P<0.02)$ than females. There was no significant correlation between the type/number of livestock owned by the community and the willingness to contribute labour and money for HAT control $(P>0.05)$. The average amount of labour and money that the respondents were willing to contribute per

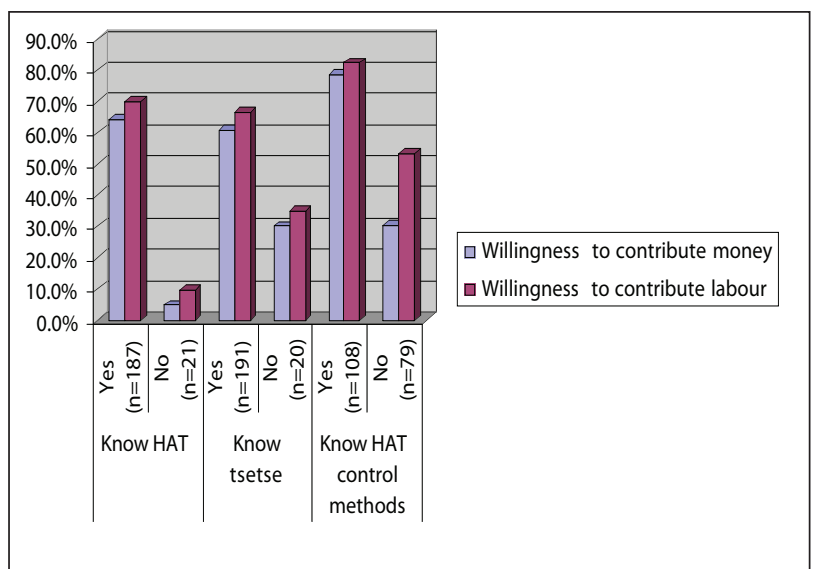

Figure 1: Community knowledge of HAT, tsetse and control and the willingness to participate in control activities and money to the HAT control activities.

\section{HAT cases reported at health facilities}

Secondary data showed that a total of 454 individuals suffered from HAT from 1999 to 2006 with the largest number of cases (143) and deaths (15) in 2004 and 2002 , respectively (Table 2). There was a decline in the number of cases and deaths from $2004-2006$.

\section{Discussion}

Before communities are engaged in active programmes for controlling tsetse and HAT, it is important that their knowledge, attitudes and practices are understood. Even in situations where the communities are sufficiently aware of trypanosomiasis and its consequences, and/or where successful tsetse and HAT control operations have been carried out, there may still be a need to increase community's awareness about known control techniques to facilitate their participation in future tsetse and HAT control activities.

Table 2: Number of HAT cases and deaths in Urambo district (1999-2006)

\begin{tabular}{|c|c|c|c|c|c|c|}
\hline \multirow[b]{2}{*}{ Year } & \multicolumn{2}{|c|}{ HAT cases } & \multicolumn{3}{|c|}{ Deaths } & \multirow[b]{2}{*}{ Total } \\
\hline & Males & Females & Total & Males & Females & \\
\hline 1999 & 1 & 0 & 1 & 0 & 0 & 0 \\
\hline 2000 & 17 & 11 & 28 & 2 & 0 & 2 \\
\hline 2001 & * & * & 38 & * & * & 3 \\
\hline 2002 & * & * & 28 & * & * & 15 \\
\hline 2003 & 71 & 28 & 99 & 2 & 5 & 7 \\
\hline 2004 & 98 & 45 & 143 & 7 & 4 & 11 \\
\hline 2005 & 56 & 29 & 85 & 3 & 0 & 3 \\
\hline 2006 & 18 & 15 & 33 & 1 & 1 & 2 \\
\hline Total & 261 & 128 & 454 & 15 & 10 & 40 \\
\hline
\end{tabular}

Data not available

month was 2.5 days (range $=0$-15days, $\mathrm{SEM}=0.20$ ) and US\$ 0.6 (range $=0-5, \mathrm{SEM}=0.08)$.

Eighty five $(40.3 \%, \mathrm{n}=211)$ respondents said that both men and women were involved in the use of target/traps. However, more adult men $(92.9 \%)$ than both adult men and women $(7.1 \%)$ were reported to be involved. This was because adult men were perceived to be stronger than women $(40 \%)$ and that women were not given an opportunity to participate (24.7\%). All nine key informants reported that, the community was willing to contribute resources in terms of labour
Findings of this study show that communities in Urambo district have adequate knowledge of human African trypanosomiasis. The community is also aware of the activities that expose an individual to tsetse bites and therefore the risk of contracting HAT. This level of awareness could be attributed to experience from patients during the previous outbreaks and education from health care personnel (Kinung'hi et al., 2006). However, in our study, there was no significant correlation between the level of education of the respondent and knowledge of HAT and its control. The main source of HAT information to the community 
was reported to be patients in the previous outbreaks and the kind of information frequently received was the symptoms/signs. This indicates that, there is a gap of knowledge delivery from reliable sources such as health care professionals to enable the community understanding the appropriate prevention techniques.

During the study period it was only in Usinga village where the active presence of tsetse flies was observed (data not shown). However, the possibility that tsetse flies were brought to Usinga and other villages by vehicles and animals can not be ignored. Tsetse could also be introduced to the villages by individuals carrying grasses and firewood from tsetse infested areas as mentioned by some respondents. Only a small proportion of the community was aware of the role played by domestic and wild animals in the transmission of HAT. Previous study demonstrated presence of human infective $T$. brucei spp circulating in game and domestic animals (Moloo et al., 1971; Kaare et al., 2002).

Despite the knowledge about HAT and the right place to seek health care, lack of health care professionals and/or diagnostic facilities in the nearest health facilities is likely to result in misdiagnosis of HAT cases. Similar findings have been reported in a study carried out in Serengeti National Park in northern Tanzania where HAT cases were mistaken for other febrile diseases like malaria (Malele et al., 2006). Majority of the respondents reported to have experienced tsetse bite which may present the risk of HAT transmission and nuisance. High number of tsetse bite per person per week was found to represent nuisance and risk for transmission of sleeping sickness for tourists and local staff in a study in Serengeti National Park in northern Tanzania (Kinung'hi et al., 2006).

Adult males were mentioned to be the most likely to suffer from HAT and the records obtained from health facilities indicated that, larger proportion of HAT patients were males. This could be due to the fact that, most of the activities (such as honey gathering, timbering, fishing, hunting and herding) exposing an individual to tsetse bite are conducted by adult men.

The use of insecticide impregnated targets was reported to be effective, easy to use and acceptable to the community. The effectiveness of this control method was substantiated by data obtained from HAT record in the health facilities, which showed a declining trend from 2004 to 2006 . However, the number of cases that are still been reported suggests that, HAT is still among important public health problems in the study area.
The findings of this study further indicate that, knowledge of tsetse flies, HAT and HAT control are amongst the important factors influencing community to contribute resources towards its control. The awareness on the major impacts of HAT in the community is also likely to be among the factors influencing community participation. Some studies have reported that knowledge of the symptoms of trypanosomiasis as an important factor influencing farmers' willingness to contribute money to tsetse control (Kamuanga et al., 1997; Pokou et al., 1999). Men are more willing than women to contribute labour and money for HAT control probably because they were reported to be most likely to suffer from the disease and were stronger than women. Men were also likely to earn more money that women and therefore, willing to contribute money to HAT control activities. Lack of opportunities for women to take part in HAT control activities indicates gender inequality among the people of Urambo district and it needs to be addressed in future control programmes.

Community participation in the disease control activities is advocated to facilitate the sustainability of the programmes. The importance of active participation and empowerment of rural communities to effective control of diseases such as malaria is well documented (Espino et al., 2004; Mlozi et al., 2006). The findings from previous study (Catley \& Leyland, 2001) indicated that, as people participated more actively, they had the option of seeking technical assistance according to their own perception of need rather than according to the external assessment by professionals. Despite the various benefits of local community participation in tsetse control, it needs to be realized that an apparent lack of serious commitment to the possible gains from community participation may be a hindrance in the sustainability of community-based control strategies. This is becauses most tsetse control projects are designed by experts with little, if any, input from the local community and extension staff. It is therefore, very crucial to involve community and extension staff in the initial design of such control programmes.

Basing on the findings of this study it can be concluded that, there is good knowledge about tsetse flies and HAT. However, little is known about the role of wild and domestic animals in the epidemiology of HAT. The community is willing to participate in the control of tsetse flies and HAT by contributing resources in terms of labour and money. In order to help communities develop appropriate tsetse and HAT control interventions, the involvement of various 
public sectors including health, livestock, agricultural professionals and allied experts is important. It is recommended to provide further education to the community on the role played by domestic and wild animals in the epidemiology of HAT, scaling up of the insecticide impregnated targets/traps with active community involvement.

\section{Acknowledgements}

In-charges of Kaliua Health Centre and Urambo District Hospital are thanked for their cooperation during the field work and for providing secondary data. We also extend our thanks to leaders of the study villages and the individual study participants whose understanding and cooperation made the accomplishment of this study possible. Thanks are also extended to Drs. S.I. Kimera and Togolai J.N.K. Mbilu for their constructive criticisms in the earlier version of the manuscript. This study received financial support from the National Institute for Medical Research, Tanzania.

Received 28 August 2007

Revised 8 December 2007

Accepted 10 December 2007

\section{References}

Barrett, J.C. (1997) Control strategies for African trypanosomiasis: their sustainability and effectiveness. In G. Hide et al., eds. Trypanosomiasis and leishmaniasis, chap. 22. London, CABI.

Bermejo, A. \& Bekui, A. (1993) Community participation in disease control. Social Science and Medicine 36, 1145-1150.

Catley, A. \& Leyland, T. (2001) Community participation and the delivery of veterinary services in Africa. Preventive Veterinary Medicine 49, 95-113.

Dietvorst, D.C.E. (1995) Community participation in the control of tsetse fly, Kalobolelwa, Western Zambia. Working Paper 95/9. Department of Veterinary and Tsetse Control Services, Western Province, Zambia.

Echessah, P.N., Swallow, B.M., Kamara, D.W. \& Curry, J.J. (1997) Willingness to contribute labour and money to tsetse control: application of contingent valuation in Busia District, Kenya. World Development 25, 239-253.

Espino, F., Koops, V. \& Manderson, L. (2004) Cотmunity Participation and Tropical Disease Con- trol in Resource-poor Settings. World Health Organization. TDR/STR/SEB/ST/04.1.

Hargrove, J.W., Omolo, S., Msalilwa, J.S.I. \& Fox (2000) Insecticide-treated cattle for tsetse control: the power and the problems. Medical and Veterinary Entomology 14, 123-130

Heller, K. (1984) Psychology and Community Change: Challenges of the Future, 2nd edition. Dorsey Press, Homewood, IL, USA.

Kaare, M.T., Picozzi, K., Welburn, S.C., Mtambo. M.M., Mellau, L.S.B., Cleaveland, S. \& Mlengeya, T.D.K (2002) Sleeping sickness in Serengeti Ecological Zone: the role of wild and domestic animals as reservoir hosts for the disease. Proceedings of the Third Annual Scientific Conference of the Tanzania Wildlife Research Institute, Arusha, December 3-5, 2002. pp 204-217.

Kamuanga, M., Sigué, H., Bauer, B., Swallow, B.M. $\&$ d'Ieteren, G. (1997) Farmers' perceptions of the impacts of tsetse and trypanosomosis control on livestock production: evidence from southern Burkina Faso. Tropical Animal Health and Production 33, 141-153

Kibona S.N., Nkya, G.M. \& Matemba, L.E. (2002) Sleeping sickness situation in Tanzania. Tanzania Health Research Bulletin 4, 27-29.

Kinung'hi, S.M., Malele, I.I., Kibona, S.N.., Matemba, L.E., Sahani., J.K., Kishamawe, C. \& Mlengeya, T.D.K. (2006) Knowledge, attitude and practices on tsetse and sleeping sickness among communities living in and around Serengeti National Park. Tanzania Health Research Bulletin 8, 168-176.

Malele, I.I, Kibona, S.N., Matemba, L.E., Sahani, K., Swilla, J. Mwalimu C.D., Mayala, B.K., Kimaro, E., Msumary, C. \& Kalinga, R.B (2006) Human African Trypanosomiasis and challenges to its control in Urambo, Kasulu and Kibondo districts, western Tanzania. Tanzania Health Research Bulletin 8, 80-85

Mboera, L.E.G., Rumisha, S.F., Senkoro, K.P., Mayala, B.K., Shayo, E.H. \& Kisinza, W.N. (2007) Knowledge and health information communication in Tanzania. East African Journal of Public Health 4, 33-39.

Mlozi, M.R.S, Shayo, E.H., Senkoro, E.H., Mayala, B.K., Rumisha, S.F., Mutayoba, B., Senkondo, E., Maerere, A. \& Mboera, L.E.G. (2006) Participatory involvement of farming communities and public sectors in determining malaria control strategies in Mvomero 
District, Tanzania. Tanzania Health Research Bulletin 8, 134-140.

Moloo, S.K., Steiger, R.F., Brun, R. \& Boreham, P.F.L. (1971) Sleeping sickness survey in the Musoma district, Tanzania. Acta Tropica 28, 189-205.

Mwangi, D.K. (1996) Socio-economic factors affecting implementation of community-managed tsetse control in Busia District, Kenya. Ph.D. thesis, University of Reading, UK.

Omolo, E.O., Ssennyonga, J.W., Ngugi, A., Kiros, F. \& Okali, C. (1995) Community mapping exercises: an evaluation. ODI Agricultural Administration (Research \& Extension) Network Paper No. 52. London, ODI.

Pokou, K., Kamuanga, M., Swallow, B.M., \& N'gbo, A.G.M. (1999) Analyse contingente de la contribution des éleveurs à la lutte contre la trypanosomose animale en Afrique de l'Ouest: le cas de la Côte d'Ivoire. Working paper No. 2. Abidjan, Cooperative Institute for Research in Environmental Sciences/University of Abidjan-Cocody. 28 pp.

SPSS Version 12 (2003) The American Statistician Vol.5, No. 4, pg 310-315.

Ssennyonga, J.W. (1994) Implementing communitybased tsetse trapping technology in Lambwe Valley, Western Kenya. In L.H. Otieno \& L. Bugembe, eds. Proc. Fourth Int. ICIPE Mobile Seminar, Addis Ababa, Ethiopia, 2730 September 1993. Nairobi, ICIPE Science Press.

Swallow, B.M. \& Woudyalew, M. (1994) Evaluating the willingness to contribute to a local public good: application of contingent valuation to tsetse control in Ethiopia. Ecol. Econ., 11, 153-161.

WHO (1991) Community Involvement in Health Development: Challenging Health Services. WHO Technical Report Series 809. WHO, Geneva. 